\title{
Design and Development of a Low Cost Solar Powered Drip Irrigation System for Auchi Polytechnic Demonstration Farm
}

\author{
Ogunnubi C. S. ${ }^{1} \quad$ Suleiman A. I. $^{2} \quad$ Otoaye A. A. ${ }^{2} \quad$ Ugbodaga Mercy E. $^{3}$ \\ 1.Department of Agricultural Technology, Auchi Polytechnic Auchi, Edo State \\ 2.Department of Agricultural and Bio-Environmental Engineering Technology. Auchi Polytechnic Auchi, Edo \\ State \\ 3.Department of Civil Engineering Technology, Auchi Polytechnic Auchi
}

\begin{abstract}
Auchi Polytechnic and the Communities surrounding her, have being experiencing significant issues with water scarcity and quality for many decades. Again, with the moribund state of the Water Corporation Service here in Auchi, there is an unprecedented demand for water concerns about water use by agriculture. Hence, a lot of farming activities takes place only during the raining season. This study aimed to design a solar powered borehole for drip irrigation system. Drip lines were laid, $2 \mathrm{~mm}$ holes was made at distance of $30 \mathrm{~cm}$ on the $6 \mathrm{~m}$ PVC pipes. Components of drip irrigation system consist essentially of main line, submains, laterals and emitters. The main line delivers water to the submains and the submains to the laterals. The set up was tested to determine the uniformity of water emission from the drip emitters into the field, maize, pepper, tomatos was used as the test crops and there was uniform growth observed across the entire field. The low cost drip system developed in this study showed a high level of efficiency and uniformity of water emission across the entire study area.
\end{abstract}

Keywords: Low Cost Solar Powered, Irrigation System, Farm

DOI: $10.7176 / \mathrm{JNSR} / 11-18-05$

Publication date:September $30^{\text {th }} 2020$

\section{BACKGROUND OF THE STUDY}

Many sources of power have contributed a great deal to lifting water for agricultural purposes, fossil fuel has been a major contribution to carbon-based climate change and air pollution. In addition, rising fossil fuel costs and energy self-sufficiency have made the development of viable sources of clean energy critical for many parts of the world. Photovoltaic-powered (PVP) pumping for crop irrigation has been suggested as an application, as it is an energy intensive activity that is well suited for implementation with renewable energy sources. However, to be practical, PVP irrigation, like all alternative energy applications, must be both technically and economically feasible. For irrigation, this feasibility is dependent on many factors, such as crop type, location, water depth, conventional energy costs, government incentives and carbon taxes.

The Drip Irrigation System using Solar-Powered pump in Auchi Polytechnic Demonstration Farm is a novel project by her staff and students. The purpose of the farm is to teach students and staff to expand their thinking about farming, new and innovative farming techniques. Instead of focusing on local and mass produced crops, which keep most small farmers living a subsistence hand to mouth lifestyle, the intended irrigation system in the Farm will teach them the value of growing cash crops that can be sold to the upcoming and ever changing multicultural market. Here in Auchi Polytechnic, we value hard work and dedication and through our own efforts, we are leading by example and both showing and teaching student that through hard work they too can improve their lives and the lives of their families.

Developing infrastructure for the water resources and their management have been the common policy agenda in many developing economies, particularly in the arid and semi-arid and tropical countries like Nigeria. A study by the International Water Management Institute(IWMI) has shown that around 50 per cent of the increase in demand for water by the year 2025 can be met by increasing the effectiveness of irrigation (Seckler et al., 1998).The review of past studies lucidly shows that the solution to the problem of growing groundwater scarcity and persistent groundwater resource degradation across regions is two-fold.

The first is the supply side management practices like watershed development, water resources development through major, medium and minor irrigation projects, etc. The second is through the demand management by efficient use of the available water both in the short-run and long-run perspectives. This includes drip irrigation and other improved water management practices. Recognizing the importance of sustainable water-use efficiency in agriculture, a number of demand management strategies (like water pricing, water users association, turnover system, etc.) have been introduced since the late-1970s to increase the water-use efficiency, especially in the use of surface irrigation water.

One of the demand management mechanisms is the adoption of micro irrigation such as drip and sprinkler methods of irrigation. Evidences show that the water-use efficiency increases up to 100 per cent in a properly designed and managed drip irrigation system (INCID, 1994; Sivanappan, 1994). Drip method of irrigation helps to reduce the over exploitation of groundwater that partly occurs because of inefficient use of water under surface 
method of irrigation. Environmental problems associated with the surface method of irrigation like waterlogging and salinity are also completely absent under drip method of irrigation (Narayanamoorthy, 2003). Drip method helps in achieving saving in irrigation water, increased water-use efficiency, decreased tillage requirement, higher quality products, increased crop yields and higher fertilizer-use efficiency (Qureshi et al., 2001; Sivanappan, 2002; Namara et al., 2005).

According to Amy, (2013); drip irrigation is one of the most efficient methods of irrigation — the water drips directly onto the soil, preventing losses due to evaporation or run-off, and if the flow rates are set correctly, water losses due to deep percolation (that is, penetrating the soil below the root system and flowing into the water table) can be minimized. This provides a moist environment for the roots which optimizes growth, while keeping the rest of the plant relatively dry, which helps prevent diseases. Furthermore, with drip systems, you can control where the water is applied, which increases water efficiency and helps minimize weed growth. Drip irrigations systems are typically about $90 \%$ efficient, as compared to sprinkler systems which are about $75 \%$ efficient. Water savings can be as high as $50 \%$ and crop yields can be increased by up to $40 \%$.

Amy, (2013) again asserted that; conventional drip irrigation systems cost between $\$ 1,200$ and $\$ 3,000$ per hectare $\left(10,000 \mathrm{~m}^{2}\right)$, which makes them inaccessible to small-scale farmers in developing countries. The low-cost drip systems available from International Development Enterprises cost less than $\$ 500$ per hectare and are available in a variety of sizes, ranging from the home garden kit, which costs only $\$ 2.50$ and covers a plot of 20 $\mathrm{m}^{2}$, to a large custom system that costs $\$ 45$ for $1,000 \mathrm{~m}^{2}$. Designed with affordability as the driving factor, the kits uses thin-walled flat plastic tubing and simple knotted-tube emitters and will last 1 to 2 years.

\section{MATERIALS AND METHODS \\ Design Concept}

The concept underlining the design is to develop a drip irrigation system that is cheap to rural farmers using low cost, readily available materials and adopting low technology which will require no special skills and will be adaptable to local environmental conditions in rural areas. The system should also be able to perform the following:

- Apply water to meet peak crop water requirement

- Maintain application and uniformity efficiencies at optimum levels

- $\quad$ Provide an energy and water efficient system to keep initial capital and operating cost as low as possible

\section{Study Selection and Field Preparation}

This study was carried out in Auchi Polytechnic, which is located between latitude $7^{0} 10^{\prime}$ and $7^{0} 20^{\prime}$ north of the equator and longitude $6^{0} 16^{\prime}$ and $6^{0} 36^{\prime}$ east of the Greenwich Meridian with an altitude of $207 \mathrm{~m}$.

Field preparation was done by clearing the field and preparing seed beds. Components of drip irrigation system consist essentially of main line, submains, laterals and emitters. The main line delivers water to the submains and the submains to the laterals. The emitters which are attached to the laterals distribute water for irrigation. The mains, submains and laterals are usually made of black polyvinyl Chloride (PVC) tubing. The emitters are also usually made of PVC materials. PVC material is preferred for drip system because it can withstand saline irrigation water and is also not affected by chemical fertilizers (Isrealson, et al., 2002).

In this design the following specifications was used as adapted from Evans, (2011):

Length of ridge (lateral) $=1 \mathrm{~m}$

Width of a ridge $=50 \mathrm{~cm}=0.5 \mathrm{~m}$

Area of a ridge $=10 \times 0.5=5 \mathrm{~m}^{2}$

Depth of a ridge $=0.5 \mathrm{~m}$

Centre to centre of a ridge $=1 \mathrm{~m}$

Operating pressure $\mathrm{H}=10 \mathrm{~m}$

Slope of lateral line $=1 \%$

No. of emitter $=10=17$ spaced at $30 \mathrm{~cm}$ equally along the lateral line 0.6 .

The laterals were laid with caution to ensure that there will be a uniform flow and distribution of water from each drip hole. Levelling instruments was used to get a good level of pipe placement on the field in the trenches. The field preparation was carried out as explained in the headings below:

Site Clearing and Ploughing: Land clearing was carried to rid the land of debris, grasses, shrubs, stumps, stones etc. The land was previously cultivated with cassava, care was taken to do a proper work of uprooting left over stems after harvest. The land was plough to a depth of $30 \mathrm{~cm}$ using a tractor mounted mould board plough.

\section{INSTALLATION OF DRIP LINES AND ERECTION OF WATER PLATFORM}

The water storage tank was positioned on a raised platform high enough to allow the water flow into the field by gravity.

Construction of Concrete Platform: The site work began with the erection of a concrete platform (stand) for the 3, 000 litres water tank. 
Installation of drip lines: There was a need for a plumber to install the drip lines. The plumber was mobilized with funds to secure the materials needed and to be installed subsequently and this was done in close supervision of the researchers.

\section{Design procedures}

\section{Capacity of drip system}

Drip irrigation system is generally not recommended to operate for more than $1.5-2.0$ hours at a stretch to avoid losses of water through leaching. The equation to estimate Capacity of Drip System is:

where,

$$
Q=A \times C U \times \frac{T}{\left(\eta_{a} \times t\right)}
$$

$\mathrm{Q}=$ Capacity of drip system, $1 \mathrm{ph}$

$\mathrm{A}=$ Total cultivated area, $\mathrm{m}^{2}$

$\mathrm{T}=$ Irrigation interval, days

$\eta_{a}=$ Water application efficiency (in fraction)

$\mathrm{t}=$ Duration of each irrigation, $\mathrm{h}$

Discharge required per plant (Qp) can simply be estimated by dividing the drip capacity (Q) by the number of plants (n) in the area $\mathrm{Qp}=\mathrm{Q} / \mathrm{n}$ (Evans, 2011)

\section{Length of main, submain and lateral lines}

Length of main, submain and lateral lines can be calculated with the help of length, width and total number of equal sized blocks in a field, as follows:

Length of main line $=$ width of block (if number of block i.e. $\mathrm{NB}=1$, in small fields)

Length of main, submain and lateral lines

- Total length of main line $(\mathrm{Lm})=(\mathrm{NB}-1) \mathrm{x}$ width of block (if $\mathrm{NB}>1)$

- $\quad$ Length of submain line $(\mathrm{Ls})=$ width of block $(\mathrm{Bw})$

- No submain if $\mathrm{NB}=1$

- $\quad$ Total length of submain $=$ Ls X NB

- $\quad$ Length of lateral line (LL) = Length of block (BL)

- $\quad$ Total length of lateral $=$ LL X NB X NR

Where, $\mathrm{NR}=$ Number of plant row per block

Number of drippers and laterals

In orchard and vegetables crops (Evans, 2011)

- Drippers are installed close to each plant

- Laterals are placed along each row of plant

- Number of laterals is taken equal to the number of plant rows

Number of laterals and drippers

Where,

$$
N L S=L S \div S
$$

NLS $=$ Number of laterals per submain

$\mathrm{LS}=$ Length of sub main pipe, $\mathrm{m}$

$\mathrm{S}=$ Spacing between two rows of laterals, $\mathrm{m}$

In large fields total number of laterals is estimated by multiplying the laterals per submain and the number of submain used

$\mathrm{NL}=\mathrm{LM} \div \mathrm{S}$ If $\mathrm{NB}=1$

$\mathrm{NL}=\mathrm{NLS} \times \mathrm{Ns}$ if $\mathrm{NB}>1$

Where,

$\mathrm{NL}=$ Total number of laterals

$\mathrm{LM}=$ Length of main pipe, $\mathrm{m}$

Numbers of plants per lateral are estimated by dividing the length of lateral pipe by the spacing between two plants (Evans, 2011)

Where,

$$
N P L=L L \div P S
$$

NPL $=$ Number of plants per lateral

$\mathrm{LL}=$ Length of lateral pipe, $\mathrm{m}$

$\mathrm{PS}=$ Spacing between two plants, $\mathrm{m}$ 
Number of drippers per plant is estimated as follow:

$$
\begin{aligned}
Q P=Q \div( & N L \times N P L) \\
& \mathrm{NDP}=\mathrm{QP} \div \mathrm{q}
\end{aligned}
$$

Where,

$\mathrm{QP}=$ Discharge required per Plant, lph

$\mathrm{Q}=$ Drip Capacity lph

$\mathrm{NL}=$ Total Number of laterals

NPL $=$ Number of Plants per lateral

NDP $=$ Number of Drippers per plant

$\mathrm{q}=$ Dripper discharge, $1 \mathrm{ph}$

Total Number of Dripper required is estimated using the equations

$\mathrm{NDL}=\mathrm{NDP} \times \mathrm{NPL}$

$\mathrm{ND}=\mathrm{NDL} \times \mathrm{NL}$

$\mathrm{NP}=\mathrm{NPL} X \mathrm{NL}$

Where,

$$
\begin{aligned}
& \text { NDL }=\text { Number of drippers per lateral } \\
& \text { ND }=\text { Total number of drippers } \\
& \text { NP }=\text { Total number of Plants } \\
& \text { NL }=\text { Total Number of laterals } \\
& \text { NPL }=\text { Number of Plants per lateral } \\
& \text { NDP }=\text { Number of Drippers per plant }
\end{aligned}
$$

In close growing field crops

In close growing field crops the whole area needs to be wetted

Drippers are used to act as a line source of water rather than a point source

In case of closely spaced field crops large number of drippers are required

Installation and operation of such a large number of drippers may pose problems

Therefore, emitting pipes or laterals within built drippers placed at 30 to $40 \mathrm{~cm}$ along the lateral pipes better suit such a situation (Evans, 2011).

In close growing field crops in close growing crops, the spacing between two drippers, laterals and number of drippers per lateral are estimated by taking into consideration the movement of water front with time in vertical and horizontal direction in the soil

In close growing field crops Spacing between two drippers and laterals in a closely spaced field crop were estimated by using the relationship, allowing $20 \%$ of overlapping of coverage's of two adjacent drippers (James, 1988, Evans, 2011)

Where,

$$
r=0.9\left[\left(3 \times q \times t \times 10^{-3}\right) \div 2\left(\theta_{f}-\theta_{i}\right)\right]^{\frac{1}{3}}
$$

$\mathrm{r}=$ Wetted radius, $\mathrm{m}$

$\theta \mathrm{i}=$ Initial moisture content of soil, per cent

$\theta \mathrm{f}=$ Final moisture content of soil, per cent

Emitter spacing is kept equal to twice the wetted radius

$\mathrm{SE}=2 \times \mathrm{r}$

Where,

$\mathrm{r}=$ Wetted radius, $\mathrm{m}$

$\mathrm{SE}=$ Emitter spacing, $\mathrm{m}$

Number of emitters per lateral may be estimated by dividing the length of lateral by the emitter spacing

Total number of emitters are then estimated by multiplying the emitters per lateral with number of lateral

Where,

$$
\begin{gathered}
N E L=\frac{L}{S E} \\
Q L=N E L \times q \\
Q S=\frac{Q}{N S} \\
N L S=\frac{Q S}{Q L} \\
N L=Q \div Q L \text { if } N B=1 \\
N L=N L S \times N S \text { if } N B>1
\end{gathered}
$$


$\mathrm{NEL}=$ Number of emitters per lateral

$\mathrm{L}=$ Length of Lateral, $\mathrm{m}$

$\mathrm{SE}=$ Emitters spacing, $\mathrm{m}$

$\mathrm{q}=$ Emitter discharge

$\mathrm{Q}=$ Drip Capacity or designed discharge

NLS $=$ Number of Lateral per sub-main

$\mathrm{NL}=$ Total numbers of Laterals

$\mathrm{QS}=$ sub main discharge, $1 \mathrm{ph}$

$\mathrm{QL}=$ lateral discharge, $1 \mathrm{ph}$

Number of fittings and accessories

- Common PVC fittings are elbow, reducer, tee, straight connector, end cap and gate valve

- Accessories for laterals includes gate valve, tee, joiner, elbow, end caps and grommet takeoff etc

- All these components are available in 4,10,12,16 and $20 \mathrm{~mm}$ sizes

- These takeouts/starter and rubber grommet are used for taking out laterals lines from submain/ main line

\section{Capacity of sub-main, lateral and main pipe}

- The capacity of each lateral pipe can be estimated by multiplying the dripper discharge to number of drippers per lateral

- Capacity of sub main pipe can be estimated by multiplying the lateral capacity to number of laterals per submain

- Capacity of main line and control head can be estimated by multiplying the submain discharge to number of sub mains placed on it

- $\quad \mathrm{Qm}=$ Qs x Ns

- Diameter of lateral pipe

- Lateral pipe is selected such that the head loss in lateral pipe is limited within 10 per cent of the operating pressure available at the head of the lateral

- Expected head loss in different diameter pipes are estimated and that smallest diameter pipe is selected in which the head losses are within 10 per cent of the operating pressure

- Lateral pipes having 10,12,16 and $20 \mathrm{~mm}$ internal diameter with wall thickness varying from 1 to $3 \mathrm{~mm}$ are used in drip irrigation system.

First a smaller diameter lateral pipe should be selected to reduce the total cost of system and the friction losses are estimated by using Equation

$$
h=\frac{\left[789000 \times\left(\frac{Q}{N_{1}}\right)^{1.75} \times l \times F_{d}\right]}{d^{4.75}}
$$

and then elevation head is added to this. If the variation in total friction losses are found within $10 \%$ of the operating pressure then selected diameter is accepted.

Where,

$\mathrm{Q}=$ Capacity of drip system, $1 \mathrm{ps}$

$\mathrm{h}=$ Frictional loss in lateral pipe, $\mathrm{m}$

$\mathrm{Fd}=$ Factor for multiple outlet (Based on number of outlets)

$\mathrm{d}=$ Diameter of lateral pipe, $\mathrm{mm}$

\section{Laying of pipe in the field}

The laterals were laid with caution to ensure that there will be a uniform flow and distribution of water from each drip hole. Levelling instruments were used to get a good level of pipe placement on the field in the trenches. As indicated in plate 1 . 


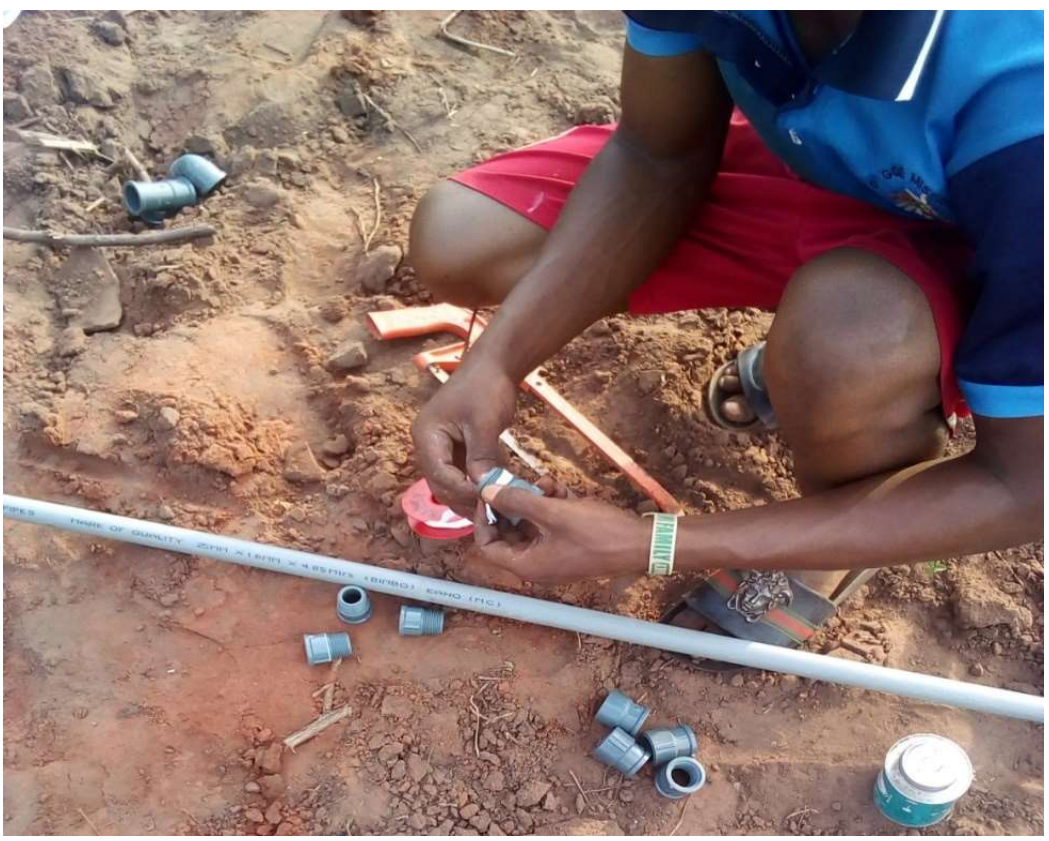

Plate 1: Installation of the emitting points and the perforated 1 inch pipe

\section{Calibration of flow in PVC pipes (tied and untied)}

To obtain a uniform flow of water from the laterals with a length of $6 \mathrm{~m}$, the pipes were calibrated to determine their uniformity of emission. To calibrate the pipe for uniformity of flow from 5 drip holes of $2 \mathrm{~mm}$ diameter each per lateral of $6 \mathrm{~m} \mathrm{x} 4=24 \mathrm{~m}$, end cap fixed at one end, elbow fixed at the other and jointed to a pipe of height $0.6 \mathrm{~m}$. This was connected to the main pipe through the elbows to supply water from the storage tank to the main laterals through the drip holes. Collector cans was used to collect water from the drip holes. The collector cans were placed on a leveled surface which was checked with a leveling device (spirit level), to ensure even distribution of water in the drip holes. The water collected from different drip lines at 5, 10, 20 and 30 minutes was measured using a measuring cylinder to check uniformity of water flow from each drip hole (Figure 1).

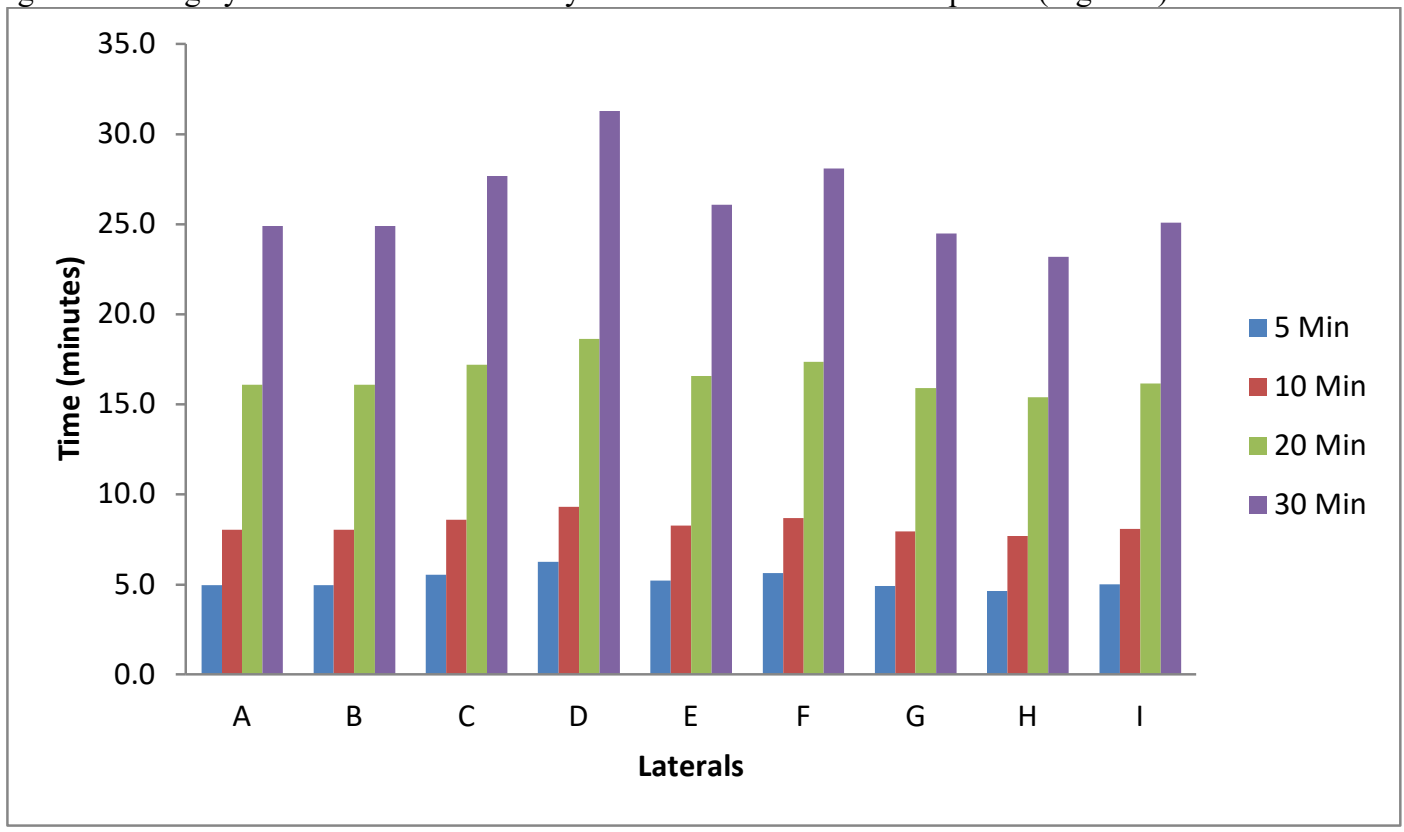

Figure 1: Average values of emitter uniformity

The results above shows a steady increase in the litres of water emitted with time. Unless there is a blockage in any of the emitters during long time operation, they are quite efficient in the uniform distribution of water over the land. Water quality and filtration are probably the most serious concerns when considering drip irrigation. In 
order to discharge very low flow rates, the diameter of the emitter orifices must be very small. This results in the emitters being blocked very easily by even the smallest contaminants in the water supply. Of particular concern are suspended solids, such as silt and sand, minerals that precipitate out of solution, such as iron or calcium, and algae that may grow in the water. Virtually every drip irrigation system must include a filtration system adequate to prevent plugging of the emitters. A system with poor quality water and poor filtration simply will not function reliably enough to warrant the maintenance requirements needed to keep it in operation. One will think that the emitter close to the main line along the lateral will yield more litres of water but as the water fills the lateral it discharges it at almost equal rate.

The hours of operation needed to meet the irrigation requirement will depend upon the flow rate of the emitting device, the irrigation interval, and the rate of consumptive water use by the crop. In no case should the total system be designed to operate more than 18 hours per day. This allows time for system maintenance, and excess capacity for catch-up in case of breakdowns. Nor should any zone be irrigated for more than 16 hours continuously, to allow some time for aeration of the crop root zone.

This low cost drip irrigation system can be an extremely versatile production tool in horticultural enterprises. It can stretch a limited water supply to cover up to 25 percent more acreage than a typical sprinkler system. It can reduce the incidence of many fungal diseases by reducing humidity in the crop canopy and keeping foliage dry. It allows automation of the irrigation system, reducing labor requirements. It delays the onset of salinity problems when irrigation water of marginal quality must be used.

This low cost system requires careful water treatment to prevent emitter blockage problems. Frequent inspection of the system is necessary to insure it is functioning properly. Improper design and component sizing can result in a system with poor uniformity of application and a much lower than expected application efficiency.

A properly designed and installed drip irrigation system will normally be substantially more expensive than a sprinkler irrigation system initially. However, the lower operating cost and higher efficiency of the drip system can justify the added expense very quickly in many horticultural production systems.

\section{PLANTING OF CROPS}

The crops planted are Maize, Tomato, Pepper and Melon. The following headings shows the agronomic steps involved in the planting and the planted crops shown in plate 2.

\section{Amount of water to apply}

Amount of water to apply was calculated based on the various growth stages of the maize variety. Rooting depth (Dr), depletion factor (Df), field capacity (FC) and permanent wilting point (PWP) were considered, resulting in the following equation;

$$
\text { Amount of water to irrigate }=D f \times(F C-P W P) \times D r \times \text { Wetted diameter }
$$

Df was considered to be $50 \%$ and Dr based on the maize and the other crops planted, the rooting depth at each growth stage of the plant. Wetted diameter of the calibrated pipe was $17 \mathrm{~cm}$.

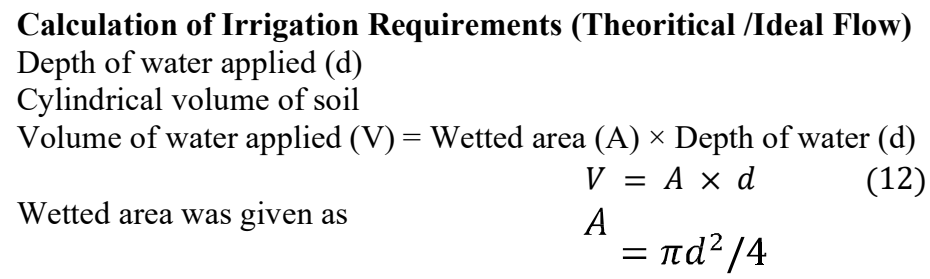

$\mathrm{A}=3.1428 \times(342 / 4)$

$\mathrm{A}=908.038 \mathrm{~cm} 2=(9080.38 \mathrm{~mm} 2)$

Volume of water applied considering the capacity of the storage tank which is 25 liters. Taking the number of drip holes on the lateral (16 drip holes); each drip hole is expected to release an amount of 1.56 liters, assuming a perfectly uniform application.

\section{Depth of irrigation water applying for 20.466 litres}

( 25 litre container was used for the calibration but because the tap was fixed closed to the bottom of the container some of the water was left at the bottom by letting 20.466 litres be collected through the catching cans and this applies to all liters used for the calibrations throughout the calibration of the pipe for $30 \mathrm{~L}, 35 \mathrm{~L}$, $45 \mathrm{~L}$ and 50L respectively ).

Volume of water applied $(V)=20.466$ liters / 16 drip holes

$$
\mathrm{V}=1.28 \text { liters } \times 1000 \mathrm{~cm} 3
$$


$\mathrm{V}=1280 \mathrm{~cm} 3($ per drip hole) Therefore depth $(\mathrm{d})$ of water applied $=\mathrm{V} / \mathrm{A}$

$$
\begin{gathered}
\mathrm{d}=1280 \mathrm{~cm} 3 / 908.038 \mathrm{~cm} 2 \\
\mathrm{~d}=1.4 \mathrm{~cm}=(14 \mathrm{~mm})
\end{gathered}
$$

\section{Depth of irrigation water applying for 24.614 litres}

Volume of water applied $(\mathrm{V})=24.614$ liters $/ 16$ drip holes

$\mathrm{V}=1.54$ liters $\times 1000 \mathrm{~cm} 3$

$\mathrm{V}=1540 \mathrm{~cm} 3$ (per drip hole) Therefore depth (d) of water applied $=\mathrm{V} / \mathrm{A}$

$\mathrm{d}=1540 \mathrm{~cm} 3 / 908.038 \mathrm{~cm} 2$

$\mathrm{d}=1.7 \mathrm{~cm}=(17 \mathrm{~mm})$

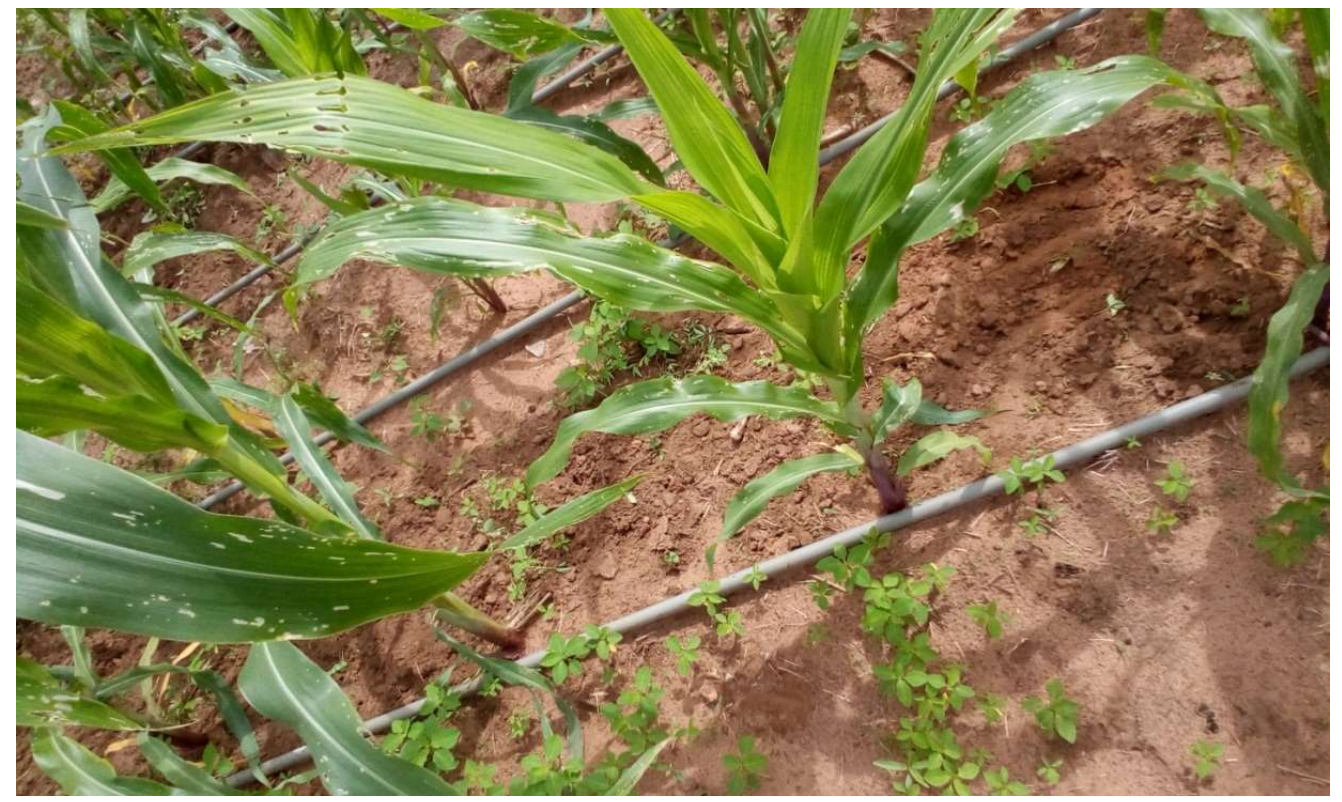

Plate 2: Planted Maize crop

The results above shows a steady increase in the litres of water emitted with time. Unless there is a blockage in any of the emitters during long time operation, they are quite efficient in the uniform distribution of water over the land. Water quality and filtration are probably the most serious concerns when considering drip irrigation. In order to discharge very low flow rates, the diameter of the emitter orifices must be very small. This results in the emitters being blocked very easily by even the smallest contaminants in the water supply. Of particular concern are suspended solids, such as silt and sand, minerals that precipitate out of solution, such as iron or calcium, and algae that may grow in the water. Virtually every drip irrigation system must include a filtration system adequate to prevent plugging of the emitters. A system with poor quality water and poor filtration simply will not function reliably enough to warrant the maintenance requirements needed to keep it in operation.

One will think that the emitter close to the main line along the lateral will yield more litres of water but as the water fills the lateral it discharges it at almost equal rate.

The hours of operation needed to meet the irrigation requirement will depend upon the flow rate of the emitting device, the irrigation interval, and the rate of consumptive water use by the crop. In no case should the total system be designed to operate more than 18 hours per day. This allows time for system maintenance, and excess capacity for catch-up in case of breakdowns. Nor should any zone be irrigated for more than 16 hours continuously, to allow some time for aeration of the crop root zone.

This low cost drip irrigation system can be an extremely versatile production tool in horticultural enterprises. It can stretch a limited water supply to cover up to 25 percent more acreage than a typical sprinkler system. It can reduce the incidence of many fungal diseases by reducing humidity in the crop canopy and keeping foliage dry. It allows automation of the irrigation system, reducing labor requirements. It delays the onset of salinity problems when irrigation water of marginal quality must be used.

This low cost system requires careful water treatment to prevent emitter blockage problems. Frequent inspection of the system is necessary to insure it is functioning properly. Improper design and component sizing can result in a system with poor uniformity of application and a much lower than expected application efficiency.

A properly designed and installed drip irrigation system will normally be substantially more expensive than a sprinkler irrigation system initially. However, the lower operating cost and higher efficiency of the drip system 
can justify the added expense very quickly in many horticultural production systems.

\section{Conclusion}

Drip or trickle irrigation refers to the frequent application of small quantities of water at low flow rates and pressures. Rather than irrigating the entire field surface, as with sprinklers, drip irrigation is capable of delivering water precisely at the plant where nearly all of the water can be used for plant growth. Because very little water spreads to the soil between the crop rows, little water is wasted in supporting surface evaporation or weed growth.

The low cost drip system developed in this study showed a high level of uniformity of water emission across the entire study area.

- The study should be repeated in the dry season when soil moisture content can be effectively monitored.

- Further studies should focus on the design performance criteria.

- There is the need to determine the long-term effects of the depth of pipe placement and depth of water application on maize growth and yield.

- Economic analysis should be under taken to determine cost and benefits of the effects of depth of pipe placement and depth of water application on maize performance.

\section{CONFLICT OF INTERESTS}

The authors have not declared any conflict of interests.

\section{ACKNOWLEDGEMENTS}

The authors would like to thank the Managements of Tertiary Education Trust Fund (TETFUND) Abuja and Auchi Polytechnic, Auchi for providing the needed funding for this research work. This type of collaboration is crucial for sustainable development at the tertiary education level in Nigeria.

\section{REFERENCE}

Amy Smith (2013) Low-Cost Drip Irrigation Technology Brief: International Development Enterprises's Irrigation System, Economic and Political Weekly 35 (42): 3775-3780.

Evans Asenso (2011) "Design and Evaluation of a Simple PVC Drip Irrigation System Using Akposoe Maize Variety as a Test Crop" A Thesis submitted to the Department of Agricultural Engineering, Kwame Nkrumah University of Science and Technology, Kumasi

INCID (Indian National Committee on Irrigation and Drainage) (1994) Drip Irrigation in India, New Delhi.

Isrealson, O. W., E. Vaughn, V. E. Hanson, 2002, Irrigation principles and practice, 3rd Edition, John Willey and Sons Inc., New York.

James, L. G., 1988, Principles of farm irrigation system design, Krieger publishing company, Krieger Drive, Malabar, Florida.

Namara, Regassa E., Upadhyay, Bhawana and Nagar, R. K. (2005) Adoption and Impacts of Micro irrigation Technologies : Empirical Results from Selected Localities of Laharashtra and Gujarat States of India Research Report 93, International Water Management Institute, Colombo, Sri Lanka.

Narayanamoorthy, A. (1997) Drip irrigation: A viable option for future irrigation development, Productivity, 38 (3): 504-511.

Narayanamoorthy, A. (2003) Averting water crisis by drip method of irrigation: A study of two water intensive crops, Indian Journal of Agricultural Economics, 58 (3): 427-437.

Qureshi, M.E,, Wegener, M.K., Harrison, S.R. and Bristow, K.L. (2001) Economic evaluation of alternate irrigation systems for sugarcane in the Burdekin delta in North Queensland, Australia, In: Water Resource Management, Eds: C.A. Brebbia, K. Anagnostopoulos, K. Katsifarakis and A.H.D. Cheng, WIT Press, Boston, pp. 47-57.

Seckler, David, Amarasinghe, Upali, Molden, David, de Silva, Radhika and Barker, Randolph (1998) World Water Demand and Supply,1990 to 2025: Scenarios and Issues, Research Report 19, International Water Management Institute (IWMI), Colombo, Sri Lanka.

Sivanappan, R.K. (1994) Prospects of micro-irrigation in India, Irrigation and Drainage Systems, 8 (1):49-58.

Sivanappan, R.K. (2002) Strengths and weaknesses of growth of drip irrigation in India, In: Proc. of Micro Irrigation for Sustainable Agriculture.GOI Short-term training 19-21 June, WTC, Tamil Nadu Agricultural University, and Coimbatore. 